\title{
A Short Discussion on Chemotherapeutic Options for Advanced-Stage Colorectal Carcinoma
} \author{
Khan $^{4 *}$ \\ ${ }^{1}$ Jinnah Medical and Dental College, Pakistan \\ ${ }^{2}$ Sandeman Provincial Hospital, Pakistan \\ ${ }^{3}$ Liaquat National Medical College and Hospital, Pakistan \\ ${ }^{4}$ Dow University of Health and Sciences, Pakistan
}

Sani Zehra ${ }^{1}$, Muhammad Uzair ${ }^{1}$, Allahyar ${ }^{2}$, Uroos Amir ${ }^{3}$, Sundas Ishaque ${ }^{3}$, Yumna Saleem Ahmad ${ }^{3}$ and Ali

Submission: September 06, 2018; Published: September 28, 2018

*Correspondence Address: Ali Khan, Dow University of Health and Sciences, Karachi, Pakistan, alikhanmedical409@gmail.com

\begin{abstract}
Globally, more than 1 million people get colorectal cancer every year resulting in about 715,000 deaths annually. It is the second most common cause of cancer in women and the third most common in men with it being the fourth most common cause of cancer death after lung, stomach and liver cancer. In advanced cancer of both the colon and rectum, chemotherapy may be used in adjuvant to surgery in certain cases. The decision to add chemotherapy in management of colorectal cancer depends on the stage of the disease. In advanced stage i.e. stage III or IV where cancer has spread to the lymph nodes or distant organs, respectively, adding chemotherapeutic agent fluorouracil, levamisole, folinic acid, leucovorin or capecitabine increases life expectancy. The drugs capecitabine and fluorouracil are interchangeable, with capecitabine being an oral medication while fluorouracil being an intravenous medicine. If the lymph nodes do not contain cancer, the benefits of chemotherapy are controversial. If the cancer is widely metastatic or unresectable, treatment is then palliative.
\end{abstract}

Fluorouracil-based adjuvant chemotherapy benefited patients with stage II or stage III colon cancer and helps in reducing the risk of relapse but adjuvant therapies have their own higher benefits like Although, the toxicities related to the therapy were significant but there were no treatment-related deaths. The aim of this study was to establish a comparison between different chemotherapeutic drugs used for the treatment of colorectal carcinoma and identify the one with best results and less adverse effects in contrast with others.

Keywords: Chemotherapeutic drugs; Colorectal carcinoma; Fluorouracil; Levamisole; Folinic acid; Leucovorin; Capecitabine

\section{Introduction}

A cancer is the abnormal growth of cells that have the ability to invade or spread to other parts of the body. Colorectal cancer is the development of cancer from the colon or rectum. Most colorectal cancers are due to old age and lifestyle factors including diet, obesity, smoking and lack of physical activity, with only a small number of cases due to underlying genetic disorders. Colorectal cancer is the fourth most common type of cancer in Western society and the second leading cause of cancer-related death in America. Almost 1 million patients receive a diagnosis of colorectal cancer yearly, Although surgical resection is potentially curative, almost half die of the cancer along with development of local or distant recurrences [1]. Each year, approximately 230,000 patients with colon cancer are eligible for adjuvant chemotherapy and those with the highest risk of recurrence are advised to receive chemotherapy, which has been shown to be beneficial in a number of trials groups.

The natural history of colorectal cancer correlates strongly with genetic alterations that occur during the progression from adenoma to carcinoma to metastatic disease. The most common genetic alterations are chromosomal amplifications, allelic losses or loss of heterozygosity, loss of the DNA mismatch-repair function and translocations. These changes result in either microsatellite instability or stability tumors [2]. The primary treatment is surgery, is possible in about $70 \%$ of patients, but patients undergoing surgery develop incurable recurrent disease. Cytotoxic chemotherapy after resection can lower the risk of recurrence. Fluorouracil has a beneficial effect as a single chemotherapeutic drug for colorectal CA, but adjuvant therapies have proved their dramatic effect over the survival and improved health status of patients suffering from colorectal carcinoma. Such adjuvant chemotherapy commonly consists of treatment with fluorouracil-containing regimens. Of the combinations tested, two of the most beneficial are fluorouracil plus levamisole and fluorouracil plus folinic acid or leucovorin [3-5]. The oral fluoropyrimidine capecitabine is an established alternative to fluorouracil and leucovorin as first-line treatment for metastatic colorectal cancer [6]. 


\section{Cancer Therapy \& Oncology International Journal}

The combination therapy of fluorouracil plus levamisole is promising because levamisole shortens the duration of postoperative immunosuppression. levamisole is easily administered orally and known to restore cellular immunity depressed by surgery. After trials, evidence has emerged of a possible detrimental effect on survival associated with levamisole [7]. The recently used regimen is FU/Leucovorin also known as folinic acid which is the standard first-line therapy for colorectal CA. The cytotoxic activity of fluorouracil is potentiated by folinic acid. Promising evidence was also reported from studies of adjuvant fluorouracil with its biomodulator, folinic acid. Supplementation of the intracellular reduced folate pool by folinic acid prolongs the competitive inhibition of thymidylate synthase by forming a stable, ternary complex of the enzyme, the cytotoxically active metabolite of fluorouracil, fluorodeoxyuracil monophosphate and reduced folate $[3,8]$. Certain studies demonstrate that although the toxicities related to the therapy were significant but there were no treatment-related deaths and these results indicated that 5FU plus low-dose leucovorin is effective in preventing tumor relapse and improving survival in patients with high-risk colon cancer [9]. Adding oxaliplatin to this regimen demonstrated a significant improvement in response rate, time to disease progression, and overall survival of patients in regard with IFL regimen [4].

The oral fluoropyrimidine capecitabine generates fluorouracil preferentially in tumor tissue through enzymatic cascade. Thymidine phosphorylase, which is more active in tumor tissue, catalyzes the final stage of conversion of capecitabine to fluorouracil which is more active in tumor tissue. As treatment for metastatic colorectal cancer, capecitabine is an established alternative to the combination of fluorouracil and leucovorin $[6,10]$.

\section{Review of Literature}

A literature review was carried out to investigate the chemotherapeutic agents for the advanced colorectal carcinoma. A Medical search of the literature was performed using the key words colorectal, advanced stage carcinoma, chemotherapeutic drugs, adjuvant therapy, treatment, and outcome. Publications in Pub-Med and references from relevant articles published between 1977 and 2018 were analyzed.

The standard therapy for rectal carcinoma is surgical, however, preoperative radio-chemotherapy will play an increasing role especially in locally advanced disease [1]. The aims of chemotherapy in patients with advanced colorectal cancer are to prolong survival, control symptoms, and improve quality of life. There is no standard therapy, route of administration, or duration of treatment. although resection of the tumor, if possible, is doubtless the best option for advanced stage cancer [11] but Chemotherapy can be administered either systemically via the intravenous or oral route or by hepatic infusion [12]. Hepatic infusion is used because the liver is usually the first site of metastatic disease in patients with colorectal cancer and may be the only site of spread in approx. $40 \%$ of patients with advanced disease [11]. There are, however, discrepancies between consensus recommendations and adjuvant treatment in the community. More potent, suitable and better tolerated chemotherapy is required, especially for elderly patients, who are less likely to receive rigorous chemotherapy. Moreover, most patients with cancer would prefer oral chemotherapy, provided efficacy is not compromised.

In colon cancer, the postsurgical treatment is decided primarily by the stage of the cancer. adjuvant treatment with fluorouracil and levamisole For node-positive (stage III) patients, reduces the risk of death significantly, as compared with surgery alone [13]. According National Cancer Institute, patients with stage III disease should be offered adjuvant fluorouracil plus levamisole therapy unless there are any contraindications. Similar benefits are seen with adjuvant treatment with fluorouracil \& leucovorin and nowadays, fluorouracil \& leucovorin is standard adjuvant treatment for stage III colon cancer. The benefits of fluorouracilbased therapy for stage II colon cancer are unclear [13].

\section{Fluorouracisl Chemotherapy}

Current studies of colorectal cancer have identified two pathways that lead to the malignant phenotype i.e. high-frequency microsatellite instability and that of microsatellite stability, which respond differently to DNA damage. These tumors with distinct pathways respond differently to chemotherapeutic agents that damage DNA.A study that used previous multicenter, prospective, randomized, controlled trials to determine the effect of fluorouracil-based adjuvant chemotherapy on microsatelliteinstability status was referred. It was found that patients with tumors exhibiting microsatellite stability or low-frequency microsatellite instability benefits from fluorouracil-based adjuvant chemotherapy, whereas such chemotherapy did not benefit patients with high-frequency microsatellite instability and may in fact have led to worse outcomes among such patients [2]. Patients with non-microsatellite instability-high tumors who received 5-fluorouracil had better survival compared with patients who were not treated [14].

\section{Fluorouracil and levamisole adjuvant chemotherapy}

Depression of immunity, independent of stage has a detrimental effect, on the prognosis of malignant diseases. The stimulation of the immune system is of therapeutic benefit, when it is applied where there is a depression of immunity and where tumor load is small. Therefore we have studied the use of immunotherapy following surgery for colorectal cancer, when it is well established that there will be depression of immunity [7]. The immunostimulant chosen for these trials was levamisole which is administered orally and it restore cellular immunity which was depressed by Surgery [15]. After commencement of the trial, evidence emerged of a possible detrimental effect on survival associated with levamisole. It was observed that the survival was increased when other factors significantly affecting survival were controlled for which included duration of symptoms before presentation, which was directly proportional to survival and tumour stage, which was inversely proportional. Therefore, the 


\section{Cancer Therapy \& Oncology International Journal}

contributions of levamisole, an anthelmintic immunomodulator were only present when tumor bulk has been reduced to a minimum by surgery. Neutropenia has been observed with levamisole, however we did not see a greater incidence of this complication than with 5FU alone. In conclusion we have found that a short postoperative course of the immunostimulant drug levamisole together with a 6-month course of adjuvant 5FU reduces the recurrence rate in colorectal cancer $[3,7,16]$.

\section{Fluorouracil and Levamisole Chemotherapy}

Fluorouracil plus leucovorin also known as folinic acid is regarded as the first line adjuvant chemotherapy for the colorectal carcinoma. Optimistic evidence was reported from studies which included adjuvant therapy with folinic acid the biomodulator of fluorouracil. It is readily converted to other reduced folic acid derivatives and it does not require the action of dihydrofolate reductase for its conversion, hence its function is unaffected. Supplementation of the intracellular reduced folate pool by folinic acid prolongs the competitive inhibition of thymidylate synthase by forming a stable complex of the enzyme, reduced folate, and the cytotoxically active metabolite of fluorouracil, fluorodeoxyuracil monophosphate. A clinical trial comparing folinic-acid modulated fluorouracil with fluorouracil alone in patients with metastatic colorectal cancer, showed a better response with adjuvant therapy. The benefits from adjuvant fluorouracil and folinic acid were supported by this clear pharmacological rationale that the activity of fluorouracil is increased by folinic acid in advanced disease by potentiation of fluorouracil by folinic acid [7]. On the basis of such results several combinations of folinic acid and fluorouracil were chosen as the experimental treatment in many adjuvant trials. Fluorouracil plus folinic acid has significantly increased the survival and event-free survival.

According to a study in which a group receiving $\mathrm{LV}+5-\mathrm{FU}$ was compared with the other group receiving fluorouracil. In Comparison the disease-free survival period for patients treated with $\mathrm{LV}+5$-FU was $73 \%$ compared with $64 \%$ for patients receiving MOF. The patient's survival rate was $84 \%$ for those randomized to receive $\mathrm{LV}+5$-FU and $77 \%$ for the MOF-treated. Apart from that a 3 year follow-up of the patients showed that those treated with LV + 5-FU had a $30 \%$ reduction in the risk of developing a treatment failure and a $32 \%$ reduction in mortality risk compared with similar patients treated with MOF [17]. Patients who received postoperative $5 \mathrm{FU}$ plus leucovorin experienced significant improvement in time taken for relapse of the disease and overall survival rate as compared with the patients taken as controls who were treated with surgery alone. Although the toxicities related to the therapy were significant but there were no treatment-related deaths. These results were in correspondence to another study and indicated that 5FU plus low-dose leucovorin is effective in preventing tumor relapse and improving survival in patients with high-risk colon cancer [9].

According to a study, at 3 years, $83 \%$ of patients who had received fluorouracil/folinic acid were alive and $71 \%$ were eventfree, as compared to controls where $78 \%$ were alive, and $62 \%$ were event-free $[5,18]$. Fluorouracil plus folinic acid are preferred over fluorouracil plus levamisole because of the shorter treatment period, and because direct randomized comparisons suggest that fluorouracil plus folinic acid is at least as effective as fluorouracil plus levamisole [8]. Table 3 shows a comparison between the adverse effects of folinic acid (leucovorin) and levamisole. Another study was performed based on the comparison of FU/ $\mathrm{LV}$ and FU/LEV that indicated a prolongation in disease-free survival in patients receiving FU/LV. In patients with Dukes' B and $\mathrm{C}$ carcinoma of the colon, treatment with LEV to FU/LV does not provide any additional benefit over and above that achieved with FU+LV. Treatment with FU/LV seems to have a small advantage of DFS and an almost similar overall survival when compared with treatment with FU/LEV. These findings support the use of adjuvant $\mathrm{FU}+\mathrm{LV}$ as an acceptable therapeutic standard in patients with Dukes' B and C carcinoma of the colon [19]. Comparison between the adverse effects of folinic acid (LV) and levamisole is given in Table 3.

To further improve the efficacy of $\mathrm{FU} / \mathrm{LV}$, Irinotecan, a topoisomerase I inhibitor and oxaliplatin, a inhibitor of DNA synthesis were used as adjuvant with FU/LV in a study. Initial treatment with irinotecan plus FU/LV significantly improved outcomes as compared with FU/LV and In March 2000 this combination was regarded as first-line therapy for advanced colorectal cancer. Soon an imbalance was detected in the number of deaths within the first 60 days of treatment, showing a higher number of deaths in the IFL control arm. Survival for patients receiving oxaliplatin did not differ from those receiving Irinotecan. The response rate of patients receiving oxaliplatin was higher than those receiving IFL.

Patients treated with IFL showed decreased rates of paresthesia's and neutropenia but higher rates of adverse effects including diarrhea, vomiting, nausea, febrile neutropenia, and dehydration, as compared to the patients treated with FU/ LV plus oxaliplatin (FOLFOX). A finding important in this trial was the statistically significant advantage in overall survival for FOLFOX compared with the control regimen of IFL. As per study, Patients treated with FOLFOX experienced the longest median survival (19.5 months) in a North American phase III trial in patients with advanced colorectal cancer. Overall, this study demonstrated a significant improvement in response rate, time to disease progression, and overall survival of patients treated with a regimen of FOLFOX as compared with the control regimen of IFL $[4,16]$. Another study compared fluorouracil plus leucovorin with FOLFOX which highlighted that fever, infection, Neutropenia, diarrhea, and vomiting were the most frequent adverse effects in the patients given FL plus oxaliplatin as compared with FL. A 23\% reduction in the risk of relapse was noticed in patients receiving FOLFOX. The probability of disease-free survival at 3 years was $78.2 \%$ and $72.9 \%$ in the group given FL plus oxaliplatin and $\mathrm{FL}$ respectively. We believe that the absence of relapse is the best indicator of efficacy, since it relates directly to the effect of the treatment under investigation [5]. 
Supporting our decision are recent results demonstrating that this approach to adjuvant therapy is less toxic than monthly bolus injections of FL and is just as effective. The improvement in efficacy and a favorable toxicity profile, suggests that FOLFOX should be considered a first-line standard of care for patients with advanced colorectal cancer $[4,5]$. In contrast certain flaws were observed in the regimen concerning the use of oxaliplatin is peripheral neuropathy. Oxaliplatin induces frequent, transient, distal paresthesia and In some cases these neurosensory symptoms increase in intensity with cumulative doses and interfered with function [5].

\section{Capecitabine Chemotherapy}

The oral fluoropyrimidine capecitabine was designed with the aim of delivering fluorouracil to the tumor cells. Capecitabine is rapidly and extensively absorbed and metabolized to 5-FU in three steps generating fluorouracil in tumor tissue more preferably as compared to normal tissues. The process is a multistep procedure involving enzymes and in its final stage of conversion, fluorouracil is catalyzed by thymidine phosphorylase. As first-line treatment for metastatic colorectal cancer, capecitabine is an established alternative to the combination of fluorouracil and leucovorin. This data provided the rationale for a trial in a study in which capecitabine plus fluorouracil and fluorouracil-plus-leucovorin regimen as adjuvant treatment in resected stage III colon cancer were compared. The primary objective was to demonstrate that capecitabine was at least equivalent to fluorouracil plus leucovorin in terms of disease-free survival. According to a study trial comparing disease-free survival in the capecitabine group with that in the fluorouracil-plus-leucovorin group was 0.87 (95\% confidence interval, 0.75 to 1.00 ).

The upper limit of the confidence interval (1.0) was significantly below predefined margins, 1.25 and 1.20, for at least equivalence $(\mathrm{P}<0.001$ for both comparisons), providing confidence that capecitabine is at least as effective as fluorouracil plus leucovorin. It was further noticed that Relapse-free survival in the capecitabine group was longer than in the fluorouracil-plusleucovorin which was $65.5 \%$ and $61.9 \%$, respectively. Although, the ratio of death in the capecitabine group when compared with the fluorouracil-plus-leucovorin group was not statistically significant. But when the adverse effects were compared there were significantly lower rates of nausea, vomiting, alopecia, and diarrhea as well as lower incidences of neutropenia and stomatitis in the settings of adjuvant treatment and metastatic disease with capecitabine except the incidence of grade 3 hand-foot syndrome which was significantly increased [6]. According to the results obtained from these studies, capecitabine has the potential to replace 5-FU/LV as standard adjuvant treatment for patients with colon cancer due to its improved safety profile.

\section{Conclusion}

Table 1: Comparison of all chemotherapeutic drugs for advanced colorectal carcinoma.

\begin{tabular}{|c|c|c|c|c|}
\hline & 5-FU & Levamisole & Leucovorin Or Folinic Acid & Capecitabine \\
\hline Medical Use & $\begin{array}{c}\text { Anal, Breast, Colorectal, } \\
\text { Oesophageal, Stomach, } \\
\text { Pancreatic and Skin Cancers } \\
\text { (Especially Head and Neck } \\
\text { Cancers), Actinic Keratoses, } \\
\text { Skin Cancers and Bowen's } \\
\text { Disease }\end{array}$ & $\begin{array}{l}\text { Anthelmintic, treatment of } \\
\text { colon cancer }\end{array}$ & $\begin{array}{l}\text { Chemotherapeutic agent } \\
\text { protects against bone } \\
\text { marrow suppression or } \\
\text { gastrointestinal mucosa } \\
\text { inflammation }\end{array}$ & $\begin{array}{l}\text { Colorectal cancer Breast cancer } \\
\text { Gastric cancer Oesophageal } \\
\text { cancer }\end{array}$ \\
\hline $\begin{array}{l}\text { Mechanism of } \\
\text { action }\end{array}$ & $\begin{array}{l}\text { Interrupting the action of } \\
\text { thymidylate synthase (TS) } \\
\text { inhibitor \& blocks synthesis } \\
\text { of the pyrimidine thymidine, } \\
\text { which is a nucleoside required } \\
\text { for DNA replication. }\end{array}$ & $\begin{array}{l}\text { It is immuno-regulatory } \\
\text { mode of action is by } \\
\text { mimicry of the thymic } \\
\text { hormone thymopoietin. it } \\
\text { may form a thymopoietin- } \\
\text { mimetic tertiary structure, } \\
\text { stimulate lymphocytes by } \\
\text { its imidazole component, }\end{array}$ & $\begin{array}{l}\text { It is readily converted to other } \\
\text { reduced folic acid derivatives } \\
\text { thus has vitamin activity } \\
\text { equivalent to that of folic acid. }\end{array}$ & $\begin{array}{l}\text { Capecitabine is metabolized } \\
\text { to 5-FU which in turn is a } \\
\text { thymidylate synthase inhibitor, } \\
\text { hence inhibiting the synthesis } \\
\text { of thymidine monophosphate } \\
\text { (THMP), the active form of } \\
\text { thymidine which is required for } \\
\text { the de novo synthesis of DNA }\end{array}$ \\
\hline $\begin{array}{l}\text { Contraindicat- } \\
\text { ions }\end{array}$ & $\begin{array}{l}\text { severely debilitated or in } \\
\text { patients with bone marrow } \\
\text { suppression, pregnant or } \\
\text { breastfeeding women }\end{array}$ & breastfeeding or pregnancy & Allergies & $\begin{array}{l}\text { hypersensitivity to fluorouracil, } \\
\text { DPD deficiency Pregnancy } \\
\text { and lactation Severe } \\
\text { leucopenia, neutropenia, or } \\
\text { thrombocytopenia Severe hepatic } \\
\text { impairment }\end{array}$ \\
\hline $\begin{array}{l}\text { Adverse } \\
\text { Effects }\end{array}$ & $\begin{array}{c}\text { Nausea Vomiting Diarrhea } \\
\text { Mucositis Headache } \\
\text { Myelosuppression Alopecia } \\
\text { Photosensitivity Hand-foot } \\
\text { syndrome Maculopapular } \\
\text { eruption }\end{array}$ & $\begin{array}{l}\text { Agranulocytosis specially } \\
\text { neutropenia, abdominal } \\
\text { pain, vomiting, headache, } \\
\text { and dizziness }\end{array}$ & $\begin{array}{l}\text { trouble sleeping, allergic } \\
\text { reactions, fever, abdominal } \\
\text { pain, vomiting, headache, } \\
\text { dizziness and allergic } \\
\text { reactions }\end{array}$ & $\begin{array}{l}\text { Appetite loss, Diarrhea, Vomiting, } \\
\text { Nausea, Stomatitis, Abdominal } \\
\text { pain, Fatigue Weakness, Hand- } \\
\text { foot syndrome, Oedemic, Fever, } \\
\text { Pain Headache }\end{array}$ \\
\hline
\end{tabular}

The results of this study illustrate that capecitabine has at least equivalent efficacy compared with IV 5-FU/LV. it also indicates that capecitabine has clinically valid safety advantages over
5-FU/LV. Baseline disease characteristics, demographic features, treatment history, and prognostic factors were similar between the two treatment groups and are consistent with those in other 


\section{Cancer Therapy \& Oncology International Journal}

studies of colorectal cancer patients who receive first line 5-FUbased chemotherapy. This study, therefore, provides a sound basis for establishing the activity of capecitabine, and the results seem to be generally applicable to patients with advanced or metastatic colorectal cancer. Since the start of study, other therapeutic agents have signified the activity in advanced colorectal cancer either as monotherapy or in combination with 5-FU. Promising results have been obtained with FOLFOX therapy in patients with advanced colorectal cancer but due to its neurotoxic symptoms, capecitabine can be preferred over it. On the basis of the successful results obtained from the oxaliplatin and 5-FU/LV therapy, the combination of capecitabine plus oxaliplatin is being studied, as well as capecitabine plus radiotherapy for rectal cancer is also being studied. On the basis of the results of the present study, we conclude that capecitabine monotherapy provides supremacy over the IV bolus 5-FU/LV in the treatment of advanced colorectal cancer, including a disease-free survival advantage, favorable toxicity profile, relapse free survival and the convenience of an oral drug that is more attractive to patients and enables a more convenient outpatient therapy (Tables 1-3).

Table 2: Complications reported with the use of chemotherapeutic drugs.

\begin{tabular}{|c|c|c|}
\hline & 5FU & FU/Levamisole \\
\hline Drug associated death & 0 & 1 \\
\hline Alopecia & 6 & 6 \\
\hline Neutropenia & 12 & 10 \\
\hline Nausea & 14 & 10 \\
\hline
\end{tabular}

Table 3: Comparison between adverse effects of Folinic acid and Levamisole.

\begin{tabular}{|c|c|c|}
\hline & Folinic acid (LV) & Levamisole \\
\hline Diarrhea & + & ++ \\
\hline Stomatitis & ++ & + \\
\hline Nausea/vomiting & + & + \\
\hline Dermatologic & + & ++ \\
\hline Cardiovascular & + & + \\
\hline Neurologic & + & ++ \\
\hline
\end{tabular}

\section{References}

1. Dworak O, Keilholz L, Hoffmann A (1997) Pathological features of rectal cancer after preoperative radiochemotherapy. Int J Colorectal Dis 12(1): 19-23.

2. Ribic CM, Sargent DJ, Moore MJ, Thibodeau SN, French AJ, et al. (2003) Tumor microsatellite-instability status as a predictor of benefit from fluorouracil-based adjuvant chemotherapy for colon cancer. N Engl J Med 349(3): 247-257.

3. Group QC (2000) Comparison of fluorouracil with additional levamisole, higher-dose folinic acid, or both, as adjuvant chemotherapy for colorectal cancer: a randomised trial. Lancet 355(9215): 15881596.
4. Goldberg RM, Sargent DJ, Morton RF, Fuchs CS, Ramanathan RK, et al. (2004) A randomized controlled trial of fluorouracil plus leucovorin, irinotecan, and oxaliplatin combinations in patients with previously untreated metastatic colorectal cancer. J Clin Oncol 22(1): 23-30.

5. Andre T, Boni C, Mounedji-Boudiaf L, Navarro M, Tabernero J, et al. (2004) Oxaliplatin, fluorouracil, and leucovorin as adjuvant treatment for colon cancer. N Engl J Med 350(23): 2343-2351.

6. Twelves C, Wong A, Nowacki MP, Abt M, Burris Iii H, et al. (2005) Capecitabine as adjuvant treatment for stage III colon cancer. N Engl J Med 352(26): 2696-2704.

7. Windle R, Bell PR, Shaw D (1987) Five-year results of a randomized trial of adjuvant 5-fluorouracil and levamisole in colorectal cancer. $\mathrm{Br}$ J Surg 74(7): 569-572.

8. Francini G, Petrioli R, Lorenzini L, Mancini S, Armenio S, Tanzini G, et al. (1994) Folinic acid and 5-fluorouracil as adjuvant chemotherapy in colon cancer. Gastroenterology 106(4):899-906.

9. O'Connell MJ, Mailliard JA, Kahn MJ, Macdonald JS, Haller DG, et al. (1997) Controlled trial of fluorouracil and low-dose leucovorin given for 6 months as postoperative adjuvant therapy for colon cancer. J Clin Oncol 15(1): 246-250.

10. Scheithauer W, McKendrick J, Begbie S, Borner M, Burns WI, et al. (2003) Oral capecitabine as an alternative to iv 5-fluorouracil-based adjuvant therapy for colon cancer: safety results of a randomized, phase III trial. Ann Oncol 14(12): 1735-1743.

11. Simmonds PC (2000) Palliative chemotherapy for advanced colorectal cancer: systematic review and meta-analysis. Colorectal Cancer Collaborative Group. BMJ 321(7260): 531-535.

12. Stelzner S, Hellmich G, Koch R, Ludwig K (2005) Factors predicting survival in stage IV colorectal carcinoma patients after palliative treatment: a multivariate analysis. J Surg Oncol 89(4): 211-217.

13. Sargent DJ, Goldberg RM, Jacobson SD, Macdonald JS, Labianca R, et al. (2001) A pooled analysis of adjuvant chemotherapy for resected colon cancer in elderly patients. N Engl J Med 345(15): 1091-1097.

14. Carethers JM, Smith EJ, Behling CA, Nguyen L, Tajima A, et al. (2004) Use of 5-fluorouracil and survival in patients with microsatelliteunstable colorectal cancer. Gastroenterology 126(2): 394-401.

15. Windle R, Wood RF, Bell PR (1979) The effect of levamisole on postoperative immunosuppression. Br J Surg 66(7): 507-509.

16. Moertel CG, Fleming TR, Macdonald JS, Haller DG, Laurie JA, et al. (1995) Fluorouracil plus levamisole as effective adjuvant therapy after resection of stage III colon carcinoma: a final report. Ann Intern Med 122(5): 321-326.

17. Wolmark N, Rockette H, Fisher B, Wickerham DL, Redmond C, et al. (1993) The benefit of leucovorin-modulated fluorouracil as postoperative adjuvant therapy for primary colon cancer: results from National Surgical Adjuvant Breast and Bowel Project protocol C-03. J Clin Oncol 11(10): 1879-1887.

18. Labianca R, Marsoni S, Pancera G, Torri V, Zaniboni A, et al. (1995) Efficacy of adjuvant fluorouracil and folinic acid in colon cancer. Lancet 345(8955): 939-944

19. Wolmark N, Rockette H, Mamounas E, Jones J, Wieand S, et al (1999) Clinical trial to assess the relative efficacy of fluorouracil and leucovorin, fluorouracil and levamisole, and fluorouracil, leucovorin, and levamisole in patients with Dukes' B and C carcinoma of the colon: results from National Surgical Adjuvant Breast and Bowel Project C-04 J Clin Oncol 17(11): 3553-3559. 
This work is licensed under Creative Commons Attribution 4.0 License

DOI: 10.19080/CTOIJ.2018.12.555831

\section{Your next submission with Juniper Publishers} will reach you the below assets

- Quality Editorial service

- Swift Peer Review

- Reprints availability

- E-prints Service

- Manuscript Podcast for convenient understanding

- Global attainment for your research

- Manuscript accessibility in different formats ( Pdf, E-pub, Full Text, Audio)

- Unceasing customer service

Track the below URL for one-step submission https://juniperpublishers.com/online-submission.php 